\title{
El Palacio Domecq de Jerez de la Frontera y el arquitecto Juan Díaz de la Guerra
}

\author{
José Manuel Moreno Arana \\ Universidad de Sevilla \\ RESUMEN: Estudio sobre el Palacio Domecq de Jerez de la Frontera (Cádiz, España), la más impor- \\ tante de las casas señoriales construidas durante el siglo XVIII en dicha ciudad. Junto a su análisis \\ formal, se aportan detalles sobre su promotor, el marqués de Montana, y su proceso constructivo, \\ documentando la intervención del arquitecto Juan Díaz de la Guerra, del que se suministran también \\ nuevos datos biográficos y profesionales
}

PALABRAS CLAVE: Arquitectura civil, Barroco, Siglo XVIII, Jerez de la Frontera, Juan Díaz de la Guerra.

\section{Domecq Palace at Jerez de la Frontera and Juan Díaz de la Guerra, the Architect}

\begin{abstract}
Study about Domecq Palace at Jerez de la Frontera (Cádiz, Spain), the most important example of the stately houses built during the eighteenth century in that city. Together with a formal analysis, details about its promoter, the Marquis of Montana, and its construction process are provided. The intervention of architect Juan Diaz de la Guerra is hereby documented with new biographical and professional data.
\end{abstract}

KEY WORDS: Civil Architecture, Baroque, $18^{\text {th }}$ Century, Jerez de la Frontera, Juan Díaz de la Guerra.

Recibido: 7 de abril de 2014 / Aceptado: 26 de mayo de 2014.

La arquitectura civil barroca levantada en la segunda mitad del siglo XVIII en Jerez de la Frontera presenta un indudable interés. Sin embargo, hasta fechas recientes casi nada se sabía sobre la construcción y autoría de las diferentes casas señoriales de ese momento ${ }^{1}$. Estos edificios son fiel reflejo de una etapa de bonanza económica que se vio favorecida por el despegue de la industria vinatera local por aquellos años. Un ámbito en el que sobresale el caso de Antonio Cabezas, marqués de Montana, una de las personas que lograron amasar mayor

\footnotetext{
* MORENO ARANA, José Manuel: «El Palacio Domecq de Jerez de la Frontera y el arquitecto Juan Díaz de la Guerra", Boletín de Arte, n. ${ }^{\circ}$ 35, Departamento de Historia del Arte, Universidad de Málaga, 2014, pp. 207-226, ISSN: 0211-8483.

1 MORENO ARANA, José Manuel, "Notas documentales para la Historia del Arte del siglo XVIII en Jerez", Revista de Historia de Jerez, n. ${ }^{\circ}$ 9, 2003, pp. 85-101. AROCA VICENTI, Fernando, "Arquitectura civil jerezana del siglo XVIII. Revisión y nuevos datos", Laboratorio de Arte, n. ${ }^{\circ} 18,2005$, pp. 327-339. AA. VV. La casa palacio Bertemati (1776-2006). Restauración y rehabilitación para sede del Obispado de Asidonia-Jerez, Jerez de la Frontera, Obispado de Asidonia-Jerez, 2007. MORENO ARANA, J. M., "Aportaciones al estudio de la arquitectura civil del siglo XVIII en Jerez de la Frontera: el Palacio de Villapanés", Laboratorio de Arte, n. ${ }^{\circ} 20,2008$, pp. 157-181.
} 
caudal gracias a este desarrollo vinícola y que fue el promotor del hoy llamado Palacio Domecq, al cual dedicamos este artículo.

Considerada la más importante de las casas jerezanas del setecientos, existen ya algunos estudios parciales por parte de Antonio Sancho Corbacho ${ }^{2}$ y, sobre todo, de Fernando Aroca Vicenti ${ }^{3}$, autores que relacionaron sus trazas con Antonio Matías de Figueroa y Pedro de Cos, respectivamente ${ }^{4}$. No obstante, es ahora cuando podemos aportar más detalles sobre su proceso constructivo, lo que nos ha permitido documentar la intervención en ella del arquitecto Juan Díaz de la Guerra.

Nuestro trabajo ha sido dividido en cuatro apartados, en los que nos acercaremos a la figura del marqués de Montana, al desarrollo de la construcción de su palacio, al análisis formal del mismo y, para acabar, a la personalidad biográfica y profesional de Díaz de la Guerra, del que se proporcionan algunas novedades.

\section{El promotor: el marqués de Montana}

Antonio Cabezas de Aranda y Guzmán nació en Jerez en torno a 17345. Martín Ferrador es el autor de la primera y más completa biografía escrita hasta ahora sobre este personaje. En ella afirma que perteneció a una familia «hidalga y antigua», si bien "la rama de que el marqués provenía de inmediato no era ni de las más pudientes ni de las más ilustres ${ }^{6}$. Sus padres se llamaban Jerónimo Cabezas de Aranda y Ana de Guzmán7. Pero mayor interés y trascendencia dentro de su trayectoria vital significó su condición de sobrino de Alonso Diego Cabezas de Aranda, fundador de "CZ», la más antigua compañía exportadora local de vino

2 SANCHO CORBACHO, Antonio, Jerez y los Puertos: estudio histórico-artístico, Madrid, Instituto de Cultura Hispánica, 1947, pp. XV-XVI y Arquitectura barroca sevillana del siglo XVIII, Madrid, Instituto Diego Velázquez, 1952, pp. 327-329.

3 AROCA VICENTI, F., Estudios para la arquitectura y urbanismo del siglo XVIII en Jerez, San Fernando, La Voz, 1989, pp. 29-43; Arquitectura y urbanismo en el Jerez del siglo XVIII, Jerez de la Frontera, Centro Universitario de Estudios Sociales, 2002, pp. 124-127 y De la ciudad de Dios a la ciudad de Baco. La arquitectura y urbanismo del vino de Jerez (siglos XVIII-XX), Jerez de la Frontera, Remedios 9 Ediciones, 2007, pp. 195-197.

4 La atribución a Figueroa quedó recogida en los dos trabajos citados de Sancho Corbacho. La posible autoría de Pedro de Cos, arquitecto municipal que se encargó de demarcar el terreno donde se levantó el palacio, fue sugerida en: AROCA VICENTI, F., "La Historia del Arte en Jerez en los siglos XVIII, XIX y XX" en CARO, Diego (coord.): Historia de Jerez de la Frontera, tomo III (El arte en Jerez), Cádiz, Diputación de Cádiz, 1999, p. 117.

5 Así se deduce de la edad de 37 años con que se le anota dentro del padrón municipal de 1771: Archivo Histórico Municipal de Jerez de la Frontera (en adelante: AHMJF), Padrones, vol. 3, año 1771, f. 152.

6 FERRADOR, Martín, «El marqués de Montana», Revista del Ateneo, n. ${ }^{\circ}$ 30, 1927, p. 6.

7 Ibidem. 
de Jerez. El futuro marqués fue socio de la misma, ascendiendo a su dirección tras la muerte de su tío ${ }^{8}$. Esta actividad mercantil, que simultaneó con su condición de labrador y ganadero, no hay duda que le granjeó grandes beneficios y, consecuentemente, una privilegiada posición económica?

Esta riqueza le facilitaría el acceso a una serie de cargos y honores. De este modo, sabemos que fue fiscal perpetuo de la Real Justicia de Jerez y capitán de las milicias urbanas de la plaza de Tarifa ${ }^{10}$. Además, ostentó en una ocasión el puesto electivo de diputado del común dentro del cabildo jerezano, gracias a la reforma político-administrativa que a partir de 1766 aplicó el gobierno de Carlos III en los ayuntamientos españoles y que permitió la entrada en ellos de miembros de una incipiente burguesía más propensa a las reformas ilustradas que la aristocracia que hasta entonces acaparaba el poder local ${ }^{11}$.

En este sentido, no hay que olvidar que apoyó el pleito liderado por el bodeguero Juan Haurie contra el gremio de vinatería local, corporación controlada por la vieja oligarquía jerezana. Este litigio, que se inicia en 1773, buscó liberalizar la producción y comercialización del vino de Jerez. De hecho, Antonio Cabezas es señalado por Maldonado Rosso como uno de los líderes de la oposición liberal en la ciudad ${ }^{12}$. Incluso puede decirse que este trasfondo parece estar detrás de la denegación inicial del terreno en el que se asentaría su palacio. Pero, aunque pueda resultar chocante con lo que acabamos de decir, Cabezas fue igualmente una persona de profundas convicciones católicas, como manifestó en su testamento, y de unas claras ambiciones aristocráticas, lo que le llevaría a obtener el título de "marqués de Montana», que le es concedido el 4 de abril de $1775^{13}$.

Un último detalle a tener en cuenta de su interesante personalidad es que puede presuponerse que tuvo ciertas inquietudes intelectuales, pues por el in-

8 MALDONADO ROSSO, Javier, La formación del capitalismo en el marco del Jerez: de la vitivinicultura tradicional a la agroindustria vinatera moderna (siglos XVIII y XIX), Madrid, Huerga y Fierro, 1999, pp. 284-288, 354.

9 De esta holgada situación se hace eco en 1773 el marqués de Villamarta ante la negativa de algunos miembros del Cabildo Municipal a conceder a Cabezas el terreno para la construcción de su palacio, declarando que era: "uno de los hombres de mayor caudal y comercio que hay en esta ciudad y todo lo gira en frutos de la misma tierra ya de crianza y labranza propia que es de mui basta extension y ya comprandole a los otros cosecheros que en el hallan su socorro por cuyos motibos mantiene de su soldada en esta ciudad y su termino diariamente mas de quinientas personas y de todo resulta que contribuye a su Magestad annualmennte mas de treinta mil ducados" (AHMJF, Actas capitulares, año 1773, f. 371).

10 FERRADOR, "El marqués...», p. 6.

11 GÓNZALEZ BELTRÁN, Jesús Manuel, Reformismo y administración local en la provincia de Cádiz durante el reinado de Carlos III: un estudio sobre la aplicación y desarrollo de las reformas en los municipios gaditanos, Jerez de la Frontera, Caja de Ahorros de Jerez, 1991, p. 173.

12 MALDONADO ROSSO, La formación..., p. 114.

13 FERRADOR, «El marqués...", p. 7. 
ventario de bienes confeccionado tras su muerte se sabe que contaba con una biblioteca de cerca de un centenar de títulos. Entre ellos, se integraban algunos en inglés y abundaban los escritos en francés, algo que se ha vinculado con su intensa relación comercial con ambos países. En cuanto al contenido, junto a la historia, la literatura y la religión, también figuran llamativamente libros sobre agricultura, producción de vino, temática militar, legislación o educación de nobles ${ }^{14}$.

Al final de su vida decide contraer matrimonio. Lo hace, a través de un poder otorgado el 17 de diciembre de 1784, con la ecijana María Josefa Ramírez Barrionuevo Lozano, hija única de José Ramírez Barrionuevo y Manuela Lozano Manzano y Pardo ${ }^{15}$. El primero, regidor perpetuo de Écija, aunque natural de Rota, era caballero notorio y poseedor de diferentes vínculos y mayorazgos ${ }^{16}$. Sin embargo, cuando meses más tarde, el 8 de mayo de 1785, el marqués redacta su testamento ya enfermo, reconoce que aún no se había verificado la consumación del matrimonio. En su última voluntad dejó estipulado que si moría sin descendencia, como así ocurrió, fundaba un patronato perpetuo que sería administrado por el cabildo de la iglesia Colegial de Jerez y que iría destinado a costear la entrada en religión de sus parientes o, en caso de no haberlos, a sufragar los hospitales de mujeres de la ciudad. Falleció el 21 de mayo de $1785^{17}$.

\section{El proceso constructivo}

Hasta ahora lo que mejor se conocía del proceso constructivo del palacio del marqués de Montana era curiosamente la fase previa al inicio de las obras. Nos referimos a la vinculada a la obtención del terreno donde el nuevo edificio se ubicaría, asunto tratado en su día por Aroca Vicenti ${ }^{18}$. La consulta directa de la

14 MORENO ARANA, Juan Antonio, Oligarquía y lectura en el siglo XVIII: La biblioteca de Manuel del Calvario Ponce de León y Zurita, regidor de Jerez de la Frontera (1794), Madrid, 2014, pp. 37-39.

15 Archivo de Protocolos Notariales de Jerez de la Frontera (en adelante: APNJF), legajo 2832, oficio IX, escribano Francisco Fernández Gutiérrez, año 1784, f. 363. Documento citado en: FERRADOR, "EI marqués...", pp. 7-8.

16 Consta esto último por un poder especial anterior del marqués, emitido el 1 de octubre de ese año, a favor de Francisco de Murcia y Córdoba, regidor perpetuo y decano de Écija, para que en su nombre firme contrato con una serie de acuerdos sobre la futura unión (APNJF, legajo 2832, oficio IX, escribano Francisco Fernández Gutiérrez, año 1784, ff. 289-291).

17 APNJF, legajo 2936, oficio XI, escribano Antonio Romero Martínez, año 1794, ff. 501-523. Su última voluntad y la evolución de este patronato fueron estudiados ya en FERRADOR, M., "El marqués...", pp. 31-34.

18 AROCA VICENTI, Estudios..., pp. 29-35. 
documentación estudiada por este autor nos ha permitido aportar una información algo más detallada ${ }^{19}$.

Fue el 15 de enero de 1773 cuando Antonio Cabezas solicita al cabido municipal jerezano dicho terreno, situado en una amplia zona sin edificar conocida como Llano de Santo Domingo o de San Sebastián. En el memorial que presenta justifica su petición por hallarse «sin casa competente para su decente abitación y notorio manejo de su labor" y por conllevar la construcción "mayor ornato de aquel sitio y el aumento de los Propios de esta ciudad con la pension annual que se estimase justa». Como él mismo aclara en su escrito, el lugar solicitado se encontraba precisamente frente a la casa en la que vivía en arrendamiento y que, como adelante veremos, terminará comprando años más tarde. El espacio pretendido debía tener forma de cuadro, de 50 varas por cada lado, y dejar por detrás una calle que lo separaría de la referida vivienda en la que habitaba en ese momento. El asunto no dejó impasibles a los capitulares, dando lugar a largas discusiones sobre si acceder a la petición o no. Se decidió finalmente que se hiciera el reconocimiento por parte del maestro mayor de la ciudad Pedro de Cos del lugar pedido.

El 29 de enero se lleva a cabo dicho reconocimiento. De Cos manifestó que no podía concederse el sitio con las dimensiones pretendidas «por estrechar demasiado las calles». De este modo, proponía que el terreno tuviera unas medidas de 47 y 42 varas por cada frente y 40 por cada lateral. Pese a esta corrección y a que el propio arquitecto aseguraba que la edificación no contradecía las ordenanzas municipales, la petición de Cabezas fue denegada por los caballeros veinticuatro por mayoría de votos, al tener en cuenta los memoriales contrarios a la obra presentados por dos particulares y por la comunidad conventual de Santo Domingo, todos ellos vecinos del referido Llano de San Sebastián, además de la opinión desfavorable de capitulares como Pedro de Mendoza y José Araos. Sus detractores señalaron toda una serie de inconvenientes. Se alude a las excesivas dimensiones del futuro palacio, las cuales reducirían la anchura de las calles y privarían de vista y luces a los edificios próximos, perjudicarían el carácter público y de recreo de la zona e incluso se dice que cortaría el curso del agua en épocas de lluvias, provocando la inundación de las casas cercanas.

Animados por la negativa municipal, el 15 de marzo de dicho año se pide por parte del convento de Santo Domingo y los vecinos la aprobación de lo acordado al Real Consejo de Castilla. Teniendo conocimiento de ello, Antonio Cabe-

19 Para las líneas que siguen remitimos a: AHMJF, Actas capitulares, año 1773, f. 371 (los diferentes folios del expediente, formado para la data a tributo del solar solicitado, están sin numerar). 
zas se dirige a la misma institución el 4 de junio siguiente solicitando de nuevo la concesión del terreno. En esta segunda petición subraya que eligió ese lugar, en el extramuros de Jerez, para poder "fabricar casas en dicha ciudad con la maior extension de sus oficinas asi para su decente habitacion como para el basto comercio que goza en mar y tierra y la gruesa labor y cria de ganados en aquel termino». Asimismo, deja bien claro cuál es el trasfondo de la negativa del cabildo a su solicitud, pues califica a Pedro de Mendoza y José Araos como sus "enemigos capitales" y hasta llega a decir que "si hubiera condescendido con facilidad de los veinte y quatros ya como hacendado particular y ya como fiscal de la Real Justicia no hay duda los hubiera tenido todos a su favorn. Es evidente que, además de su oposición al gremio de la vinatería por ese mismo tiempo, el hecho de haber ostentado el cargo de diputado del común en el Ayuntamiento le valió enemistades entre la oligarquía jerezana.

El 11 de abril de 1774 se emite un real despacho favorable a Cabezas, ordenándose "que en adelante no se impidiese con frívolos pretextos la construcción de casas y aumento de la población". Así, se le otorga un total de 1.880 varas cuadradas sobre el lugar solicitado, formando un rectángulo de 47 varas en el frente y la trasera y de 40 varas en las fachadas laterales, según queda reflejado en un plano que acompaña a este documento, en el que aparece asimismo representado todo el contexto urbano del edificio proyectado y las distancias correspondientes con las construcciones aledañas [1]. El 19 de abril Antonio Cabezas presenta dicho real despacho en el Ayuntamiento y pide que se cumpla. En el cabildo del día siguiente es leído y aceptado, procediéndose el 23 de abril al acordelamiento del ansiado terreno. En este acto se vuelve a corregir por parte de Pedro de Cos las dimensiones, aunque manteniendo las 1.880 varas cuadradas concedidas, ya que se consideró que la esquina a la calle Sevilla resultaba demasiado saliente e impedía la vista recta hacia la misma. De este modo, finalmente, las fachadas delantera y trasera serían más estrechas, con 43 varas, y se ensancharían las laterales, pues la izquierda, en la calle Sevilla, alcanzaría las 45 varas y media y la derecha, que daría a la conocida hoy como plaza Aladro, tendría 42. El 28 de mayo de 1774 se firma por fin la data a tributo correspondiente, que establece el pago de un tributo anual de 15.040 reales.

Según Sancho Corbacho, la construcción se inició en 1775 y finalizó en 1778. Desconocemos cuál pudo ser la fuente de estos datos, ya que no los cita en ningún momento ${ }^{20}$. Portillo, por su parte, afirma que se estaba labrando en

20 SANCHO CORBACHO, Arquitectura..., p. 327. 


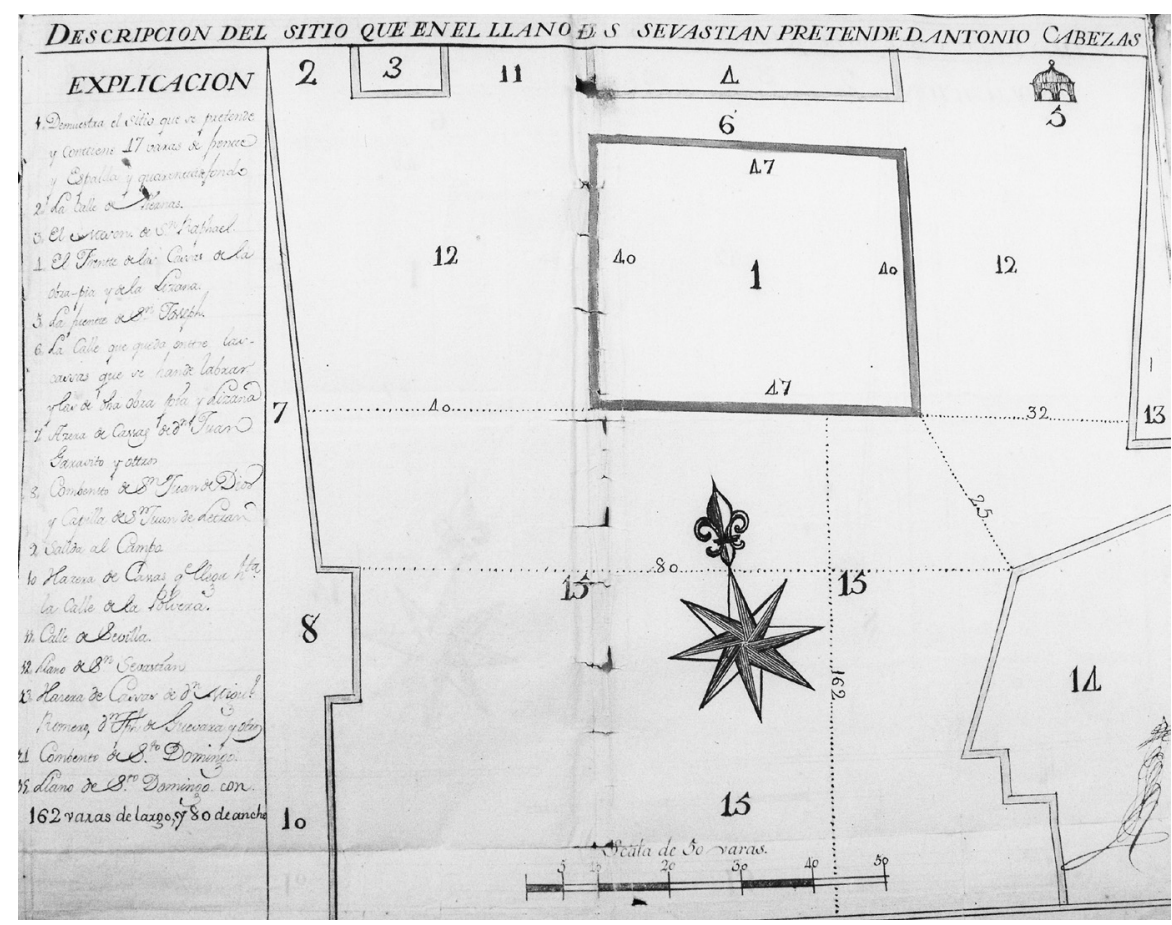

1. Plano de demarcación del terreno del palacio (1774)

1776 y que la obra duró cinco años ${ }^{21}$. Podemos confirmar que las obras estaban en curso efectivamente a fecha de 24 de julio de 1776. En ese día se produce la venta al convento de Santo Domingo de una "casa bodega y solar» aledaños por parte del clérigo de menores Vicente de Herrera. En la escritura se afirma que las mismas daban antes al Llano de San Sebastián pero entonces hacían esquina "a la calle que ahora llaman de Cavezas [...] con el motibo de estarse construiendo de nuebo unas casas grandes delante por el señor don Antonio Cavezas y Guzman Marques de Montana ${ }^{22}$.

Ya dijimos que el marqués vivía en un edificio colindante. De hecho, ese mismo año, el 21 de marzo de 1776, Antonio Cabezas lo compra al convento de

21 PORTILLO, Joaquín, Concisos recuerdos de Jerez de la Frontera. Año de 1847, Jerez de la Frontera, Ayuntamiento, 1991, p. 35.

22 APNJF, legajo 2766, oficio VI, escribano Diego Flores Riquelme, año 1776, f. 383. 
Santo Domingo. Estaba formado por unas "casas principales y bodegas» ${ }^{23}$. Con esta operación de compra pudo tener en mente una futura anexión al palacio que estaba construyendo. Parece confirmarlo el hecho de que años más tarde, el 28 de octubre de 1782, la callejuela "de Cavezas» fuera finalmente enajenada a favor del marqués ${ }^{24}$. En este sentido, es interesante señalar que en la petición que hace al Ayuntamiento, firmada el 25 de septiembre de ese año, apunta que en esa fecha la "casa principal» estaba ya construida y que había "determinado pasar a habitarla ${ }^{25}$.

Por tanto, el palacio estaba acabado a finales de 1782, al menos en lo fundamental. Pero, como veremos a continuación, el término total de las obras debió de alargarse en el tiempo, hasta el punto de que tras la muerte de su dueño en 1785 quedaban pagos y detalles pendientes. Asimismo, todavía en 1784 se adquirieron una casa y dos bodegas junto a las anteriores posesiones ${ }^{26}$, por lo que, unido a la incorporación de la indicada calle, se formó un extenso y desigual conjunto arquitectónico sobre el que fue necesario actuar.

Tras el fallecimiento del marqués quedó bajo la administración de sus bienes su albacea, Francisco Antonio de la Tixera. Los autos originados por el inventario de las propiedades de Cabezas, protocolizados en 1794, recopilan asimismo las deudas del difunto que quedaban por saldar y los gastos posteriores efectuados por el administrador ${ }^{27}$. De esta manera, el 17 de julio de 1790 se recogen en la documentación unas cuentas sobre «las obras que se hallaban pendientes y siguieron hasta el fallecimiento del Señor Marques de Montana». El interés de las mismas consiste en el pago que se anota a «Don Juan Diaz maestro alarife" por el valor de 3.000 reales, resto "de la cuenta que con él se ajustó con el motivo de haverlo sido en la construcción de las cassas prinzipales y demás obras de dicho Señor difunto". Asimismo, se incluyen otras retribuciones. De este modo, se apuntan los 3.105 reales que faltaban por pa-

23 Ibid., f. 139. Documento citado en: FERRADOR, «El marqués...», p. 7.

24 AHMJF, Actas capitulares, año 1782, ff. 659-672. Aportamos la referencia documental sobre este asunto, sin publicar hasta ahora, si bien hay que decir que Ferrador dio ya el dato, aunque con una fecha errónea (FERRADOR, "El marqués...», p. 7). Por su parte, Aroca Vicenti ha apuntado que la anexión se produjo efectivamente en 1782, aunque no da detalles (AROCA VICENTI, De la ciudad..., p. 196).

25 Solicitó cerrar al paso a esta estrecha calle con la excusa de que corría peligro de convertirse en una "atalaya" para malhechores (AHMJF, Actas capitulares, año 1782, ff. 661-662).

26 Las dos bodegas fueron adquiridas en data a censo al veinticuatro Juan Manuel de León Garabito el 23 de febrero y la casa fue comprada a Catalina e Isabel Caballero el 25 de octubre (APNJF, legajo 2832, oficio IX, escribano Francisco Fernández Gutiérrez, año 1784, ff. $42-78$ y 313)

27 APNJF, legajo 2936, oficio XI, escribano Antonio Romero Martínez, año 1794, f. 500. Este documento, además de por Martín Ferrador, fue citado en: AROCA VICENTI, Estudios..., p. 41, nota 8. No obstante, los datos que a continuación aportamos han permanecido inéditos. 
gar al alemán José Wiersich ${ }^{28}$ por "todos los cristales que puso para las casas principales" y se constata que se invirtieron además 4.081 reales, que incluían "distintos reparos y metida de rejas, pintura y blanqueo y enlosado y empedrado en el costado a la calle de Sevilla». Otras partidas hablan de reparos en las casas y bodegas contiguas. Se manifiesta que todas las cuentas anteriores "se han llevado con inteligencia y dirección de las obras menzionadas de dicho Maestro Alarife Don Juan Diaz» ${ }^{29}$.

El 10 de junio de 1791 el propio Juan Díaz de la Guerra firma otras cuentas por obras «en unas casas que fueron de la havitacion del Señor Marqués de Montana y están a la espalda de las que ultimamente labró dicho Señor y faIleció en ella, las que se hallaban sus techos ruinosos y el edificio quebrantado en todas sus paredes, que algunas han sido preciso renovarlas", todo ello por 43.080 reales $^{30}$. No hay duda de que esta partida hace alusión a los inmuebles comprados por el marqués en 1776.

Con posterioridad, el Cabildo Colegial, a cuyo cargo estaba el patronato creado para gestionar las decisiones testamentarias del marqués, arrendaría el palacio, instalándose en él las oficinas de la Administración de Rentas, Real Aduana y Despacho de la Sal ${ }^{31}$. Sin embargo, el edificio terminó siendo comprado en 1855 por Juan Pedro Domecq Lembeye. A partir de entonces y hasta 1964 fue habitada por los Domecq, familia de bodegueros de la que tomaría el palacio su nombre actual. Aroca Vicenti informa de que sufrió reformas a principios del siglo XX por parte del arquitecto Francisco Hernández-Rubio y que, tras pasar a propiedad de la firma bodeguera Domecq, en 1964 pierde su uso residencial y sufre nuevas transformaciones por Vicente Masaveu ${ }^{32}$. Sería entonces cuando se derriba el conjunto de edificaciones de la parte trasera, hoy ocupada por un jardín. Finalmente, fue en 2003 declarado bien de interés cultural ${ }^{33}$.

28 Sobre Wiersich, que ejerció también el oficio de dorador, ver: MORENO ARANA, J.M., La policromía en Jerez de la Frontera durante el siglo XVIII, Sevilla, 2010, pp. 163-165.

29 APNJF, legajo 2936, oficio XI, escribano Antonio Romero Martínez, año 1794, ff. 707-708. Se informa que Díaz actuó también en otros inmuebles propiedad del marqués en las calles Clavel, Antona de Dios, plaza de los Angustias y Sancho Vizcaíno, al igual que en el Cortijo de la Haza de Teresa y en la Hacienda del Almocadén o Matamoros.

30 lbid., ff. 831-832.

31 Al respecto, podemos recordar el comentario que hizo el ilustrado Antonio Ponz por aquellos años sobre el edificio, al que se refiere como "una suntuosa, pero ridícula casa, en la qual se han agregado varias Oficinas de Rentas Reales. Conté treinta columnas entre las del patio y fachada. Solo faltó un hábil Arquitecto que hiciese buen uso de tan excelentes materiales" (PONZ, Antonio, Viage de España, tomo XVII, Madrid, 1792, p. 259).

32 AROCA VICENTI, De la ciudad..., p. 196

$33 B O E$, n. ${ }^{\circ} 42$, Madrid, 18 de febrero de 2003, pp. 6.689-6.690. 


\section{Análisis del edificio}

La primera cuestión a tener en cuenta es su protagonismo dentro del entorno urbano en el que se sitúa ${ }^{34}$. Ya vimos que la elección del lugar para su construcción fue polémica. El antiguo Llano de San Sebastián comprendía un extenso espacio a la salida de una de las puertas de la muralla medieval, la de Sevilla, Ilamada así precisamente por conducir al camino hacia esa ciudad. Marcaba, por tanto, una de las entradas principales a Jerez. Una zona de esparcimiento, pero también de muladares y ejidos, justo en el límite entre las dos collaciones del extramuros, Santiago y San Miguel, que eran además las más habitadas. Escoltada a cada lado por los conventos de Santo Domingo y San Juan de Dios, era, en definitiva, un espacio muy transitado pero con grandes precariedades. A lo largo de la segunda mitad del siglo XVIII se dieron una serie de actuaciones que vinieron a reordenar toda esta área urbana. Pero de todas ellas la más destacada fue la edificación del palacio de Antonio Cabezas pues, como ha estudiado Aroca Vicenti, generó una clara división del espacio, un frente monumental, muy del gusto del escenográfico urbanismo barroco, entre las actuales alameda Cristina, calle Sevilla y plaza Aladro ${ }^{35}$. Un efecto similar al que el propio Juan Díaz pudo conseguir con la reforma que entre 1766 y 1776 se lleva a cabo en el jerezano Palacio de Villapanés al levantar su fachada a la calle Cruz Vieja ${ }^{36}$.

El edificio tiene una planta cuadrangular, si bien de proporciones algo irregulares. Al margen de las distintas reformas que hayan podido darse a lo largo de su historia, conserva una cierta simetría en su distribución interior, marcada por un eje central en el que se enlazan la portada, el zaguán, el patio y la escalera principales, un segundo patio más pequeño y la salida al actual jardín [2]. En alzado se superponen tres cuerpos, siendo el tercero (el sobrado o soberado) de menor altura que los restantes [3]. Asimismo, en las fachadas laterales se incluye un entresuelo coincidiendo con la zona trasera. La fachada posterior, que como vimos daba en origen a una callejuela, tiene un trazado menos cuidado y es posible que haya sido alterada en la última gran restauración, en la que se derribarían las construcciones que daban a esta zona [4],

34 Este asunto ha sido estudiado en: AROCA VICENTI, Arquitectura y urbanismo..., pp. 122-127.

35 Ibid., pp. 122-127. Desgraciadamente, intervenciones modernas a base de arbolado, mobiliario urbano y monumentos escultóricos han roto las amplias perspectivas de las que gozó el edificio en su origen.

36 MORENO ARANA, "Aportaciones...". Sobre el impacto urbano de este palacio ver: AROCA VICENTI, Arquitectura y urbanismo..., pp. 132-135. 


Farticullos

2. Planta del palacio (publicada en: SANCHO CORBACHO, Antonio:

Arquitectura barroca sevillana del siglo XVIII, Madrid, 1952)

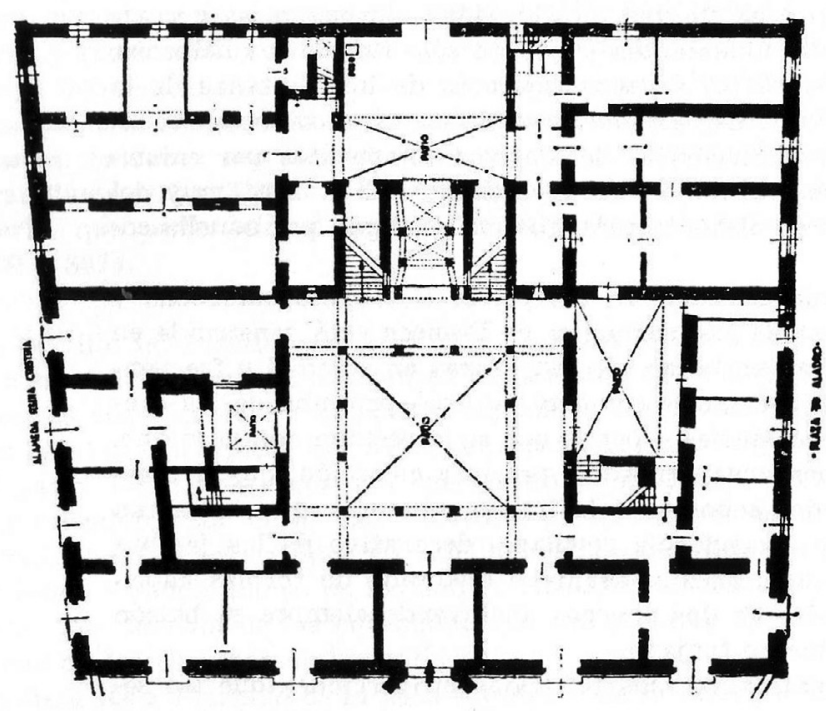

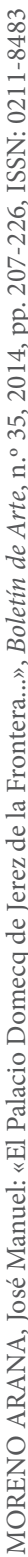




\section{- artículos José Manuel Moreno Arana}

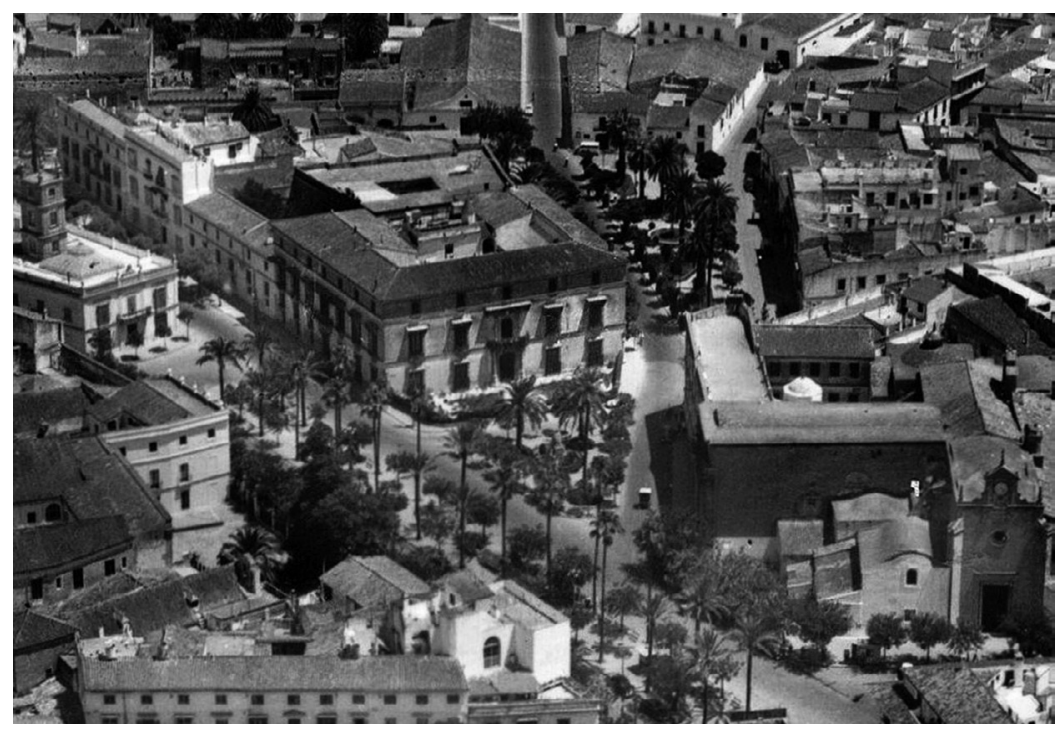

4. Vista aérea del palacio y su entorno a mediados del siglo XX (pueden verse las desaparecidas construcciones anexas a la trasera del edificio)

sobre las que también intervino Díaz y de las que sólo quedan los muros exteriores de sus cuerpos bajos ${ }^{37}$.

Con motivo de la venta del palacio en 1855 se redactó una detallada descripción del mismo que ayuda a comprender la disposición y uso de los distintos espacios. De este modo, la planta baja debió de dedicarse a la administración de los negocios del dueño y al servicio de la casa. Los tres patios menores, situados en torno al mayor, servirían para distribuir estas funciones. El documento especifica que en esa fecha las dos crujías bajas y entresuelos de los laterales tenían su acceso por la calle Sevilla y la actual plaza Aladro, respectivamente, permaneciendo separadas de la parte principal de la casa. Al patio trasero daban los cuartos y escusados para los criados, las cuadras para caballos y mulos o la cochera. La planta superior, como es lógico, se concebiría como el sitio más

37 El muro que perdura en la calle Sevilla conserva vanos, correspondientes a un entresuelo, de los que penden placas recortadas de gusto dieciochesco. Por algunas fotografías antiguas, como la que adjuntamos, puede comprobarse que esta fachada estuvo rematada por un segundo cuerpo de menor altura que el del palacio anexo. El lado a la plaza Aladro tenía un aspecto menos uniforme. Sería ahí donde se situaban las bodegas de las que habla la documentación. 


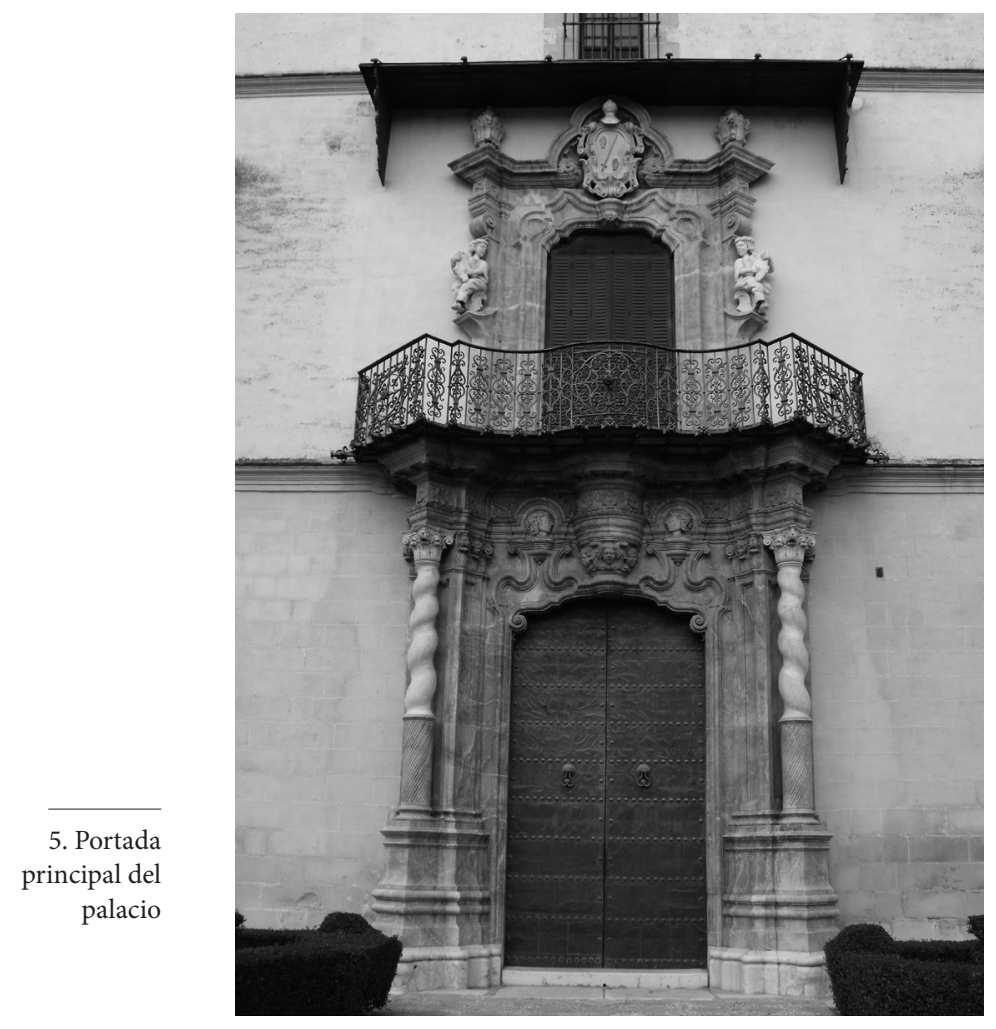

privado de la vivienda. Aquí se citan el dormitorio, el gabinete, el comedor o la sala y la cocina principales. El soberado, por último, se empleó para almacenes de granos, pajar y tendedero de ropa. La escritura aporta también algunos datos sobre materiales, hablándonos del empleo de solería de "lozas de Génova", "mármol de colores de Ytalia» para la escalera y las columnas del patio principal o «madera de segura y bovedillas» para los techos ${ }^{38}$.

A nivel estético, en el exterior el elemento más llamativo es la portada de la fachada principal [5]. Sigue el modelo de las del palacio Bertemati de la misma ciudad (h. 1768-1772), obra de Juan de Bargas, es decir, una dinámica estructura de dos cuerpos, con un vano inferior flanqueado por soportes en posición ses-

38 APNJF, legajo 3.572, oficio XI, escribano Salvador Jesús Escudero, año 1855, ff. 519v-535 (documento citado en: AROCA VICENTI, De la ciudad..., p. 196). El edificio se valoró entonces en 962.680 reales. En la actualidad los espacios más nobles del palacio se cubren con ricos artesonados de madera que suponemos que pertenecen a una reforma posterior. 
gada y un balcón superior de ondeante planta. Un dinamismo en la colocación de los soportes que también aplicó Juan Díaz en la portada de la iglesia de San Francisco (1771-1787). En Domecq las mayores singularidades están en el uso del mármol y la columna salomónica. El primero sólo se emplea dentro de la arquitectura civil jerezana en el palacio de Villapanés, donde sabemos que trabaja igualmente Díaz en 1776. La columna salomónica tallada en piedra fue utilizada raramente en Jerez, aunque fue usada también por Juan de Bargas en la espadaña de la parroquia de Santiago $(1760)^{39}$. Asimismo, son muy peculiares los motivos escultóricos, como los capiteles de las pilastras, de un orden compuesto que incluye cabezas humanas; o los dos bustos de perfil tocados con coronas de laurel que figuran en el entablamento inferior, tema decorativo que se repite en el interior, en los dos arcos de acceso a la escalera, y que responde a los gustos del comitente, ya que en su biblioteca poseía una Historia de las medallas, quizás la escrita por Carlos Patin y publicada en castellano en 1771, que incluye grabados que pudieron servir de inspiración para esta ornamentación ${ }^{40}$.

También genuinos de este palacio son los movidos balcones que se abren en el segundo cuerpo de las fachadas frontal y laterales. Las originales ménsulas que los sostienen, de ondulantes molduras acabadas en un pinjante central redondeado, recuerdan a las que encontramos en el interior de la iglesia de San Francisco. La pequeña portada que se abría a lo que hoy es la plaza Aladro está igualmente en la línea de la producción de Díaz. Plana y levemente resaltada del muro, incorpora una ventana sobre ella y describe un dibujo mixtilíneo a los lados, como vemos en el exterior de la sacristía de San Marcos o en la fachada derecha de Villapanés. Sin embargo, aquí existe un mayor refinamiento en el diseño, gracias a la inclusión de sendas volutas, con jarrones y pinjantes a eje, todo ello de un elaborado dibujo oblicuo o en perspectiva [6].

Pero la mayor riqueza decorativa del edificio la hallamos en el interior, concretamente en el patio mayor, que es, de hecho, el más suntuoso de los construidos en el Jerez del siglo XVIII [7]. Compositivamente y hasta en determinados detalles se ha tenido en él muy en cuenta el principal de Bertemati. De planta cuadrada, consta de dos cuerpos. En el bajo se abren tres arcos de medio punto por cada lado, sostenidos por columnas toscanas de mármol rojo. Las arquerías están talladas en piedra con gran profusión ornamental: los trasdoses reciben

39 AROCA VICENTI, Arquitectura y urbanismo..., pp. 215-216.

40 PATIN, Carlos: Historia de las medallas o introducción al conocimiento de esta ciencia, Madrid, 1771. Aparece reflejado en el inventario de sus libros en: APNJF, legajo 2936, oficio XI, escribano Antonio Romero Martínez, año 1794, f. 579 (documento citado en: MORENO ARANA, J.A., Oligarquía..., pp. 37-39). 
6. Portada de la fachada de la plaza Aladro

una moldura polilobulada, las enjutas están ocupadas por rocallas y en las claves están colocadas diferentes cabezas en relieve. Estas representan diversas testas humanas y monstruosas con un cierto interés por la caracterización. Al igual que ocurre con los relieves que se hallan en las dos esquinas de la fachada principal, es probable que sean más que un mero adorno sin significación y exista detrás un programa iconológico que por ahora se nos escapa. Baste comentar que en el arco central que se halla delante de la escalera se ha colocado un personaje masculino con sombrero alado, tal vez una representación de Mercurio, el dios romano del comercio, lo que a su vez podría aludir a la actividad mercantil del propietario de la casa. Ya en el cuerpo superior se abren a eje con los arcos inferiores balcones enmarcados por medias columnas sobre las que recaen medios puntos. Estas columnas adquieren una forma abalaustrada al poseer el tercio inferior del fuste abombado. Es un tipo de soporte que, aunque con diferente di- 
seño, también usa Díaz en la portada de San Francisco. Todos los arcos que dan al patio, incluidos los de la escalera, tienen la peculiaridad de acabar enrollados en sendas volutas sobre los capiteles. Es una tipología que ya Sancho Corbacho puso en relación con la obra del sevillano Ambrosio de Figueroa ${ }^{41}$. Con todo, es un modelo que se debió de difundir a través de estampas o de tratados tan conocidos en la época como Perspectivae pictorum et architectorum de Andrea $\mathrm{Pozzo}^{42}$. Este pormenor nuevamente vuelve a remitir al palacio Bertemati, en concreto al ampuloso arco de entrada a su escalera principal. Pero más curioso aún es el hecho de que la disposición oblicua del intradós del arco de Bertemati se repita en los accesos a la escalera de Domecq.

La escalera principal es de mármol y de doble tiro, dejando en medio un pasillo, abovedado y sostenido por una serie de columnas pareadas, que conduce al patio trasero. Este pasillo presenta un gran interés por su teatral concepción en perspectiva, gracias a la colocación sesgada de sus soportes dentro de tres tramos trapezoidales y desiguales entre sí. El primero de ellos aparenta de lejos ser más amplio y su cubierta simula una media naranja sobre pechinas, cuando en realidad es un cuarto de esfera de escasa profundidad ${ }^{43}$. Arquitectura ilusionista y arquitectura real quedan fusionadas de este modo. De nuevo Pozzo o grabados de escenografías teatrales de autores como Giuseppe Galli Bibiena ${ }^{44}$ pudieron acaso inspirar este sofisticado detalle. Podemos vislumbrar, por tanto, un evidente interés por la perspectiva arquitectónica en el tracista del edificio, algo que queda patente asimismo en el diseño oblicuo de los referidos arcos de la escalera y, muy especialmente, de la pequeña portada que se abría a la plaza Aladro. Inquietudes que parece que también estuvieron latentes en Juan de Bargas a la hora de concebir el Palacio Bertemati, como ha estudiado Pinto Puerto ${ }^{45}$.

Pero no podemos finalizar sin subrayar que los datos con los que ahora contamos permiten aceptar que el arquitecto que levantó el palacio fue Juan Díaz de la Guerra. La documentación lo cita claramente como el maestro alarife que había dirigido "la construcción de las cassas principales" del marqués de Montana. En este sentido, hemos visto que existen algunas afinidades con su producción documentada. Sin embargo, no es menos cierto que los paralelismos estéticos con el Palacio Bertemati llegan a ser todavía más notorios. Aun

41 SANCHO CORBACHO, Arquitectura..., p. 328.

42 POZZO, Andrea, Perspectiva pictorum et architectorum, segunda parte, Roma, 1700, fig. 41.

43 Salvando las distancias, es un recurso que recuerda al que empleó Bernardo Simón de Pineda en el retablo mayor del Hospital de la Caridad de Sevilla (1670-1673) para el fingido baldaquino central.

44 GALLI BIBIENA, Giuseppe, Architetture e prospettive, París, 1740.

45 PINTO PUERTO, Francisco, "La arquitectura de la casa Bertemati», en AA. VV., La casa..., pp. 108-111. 
7. Vista del patio y la escalera principales del palacio

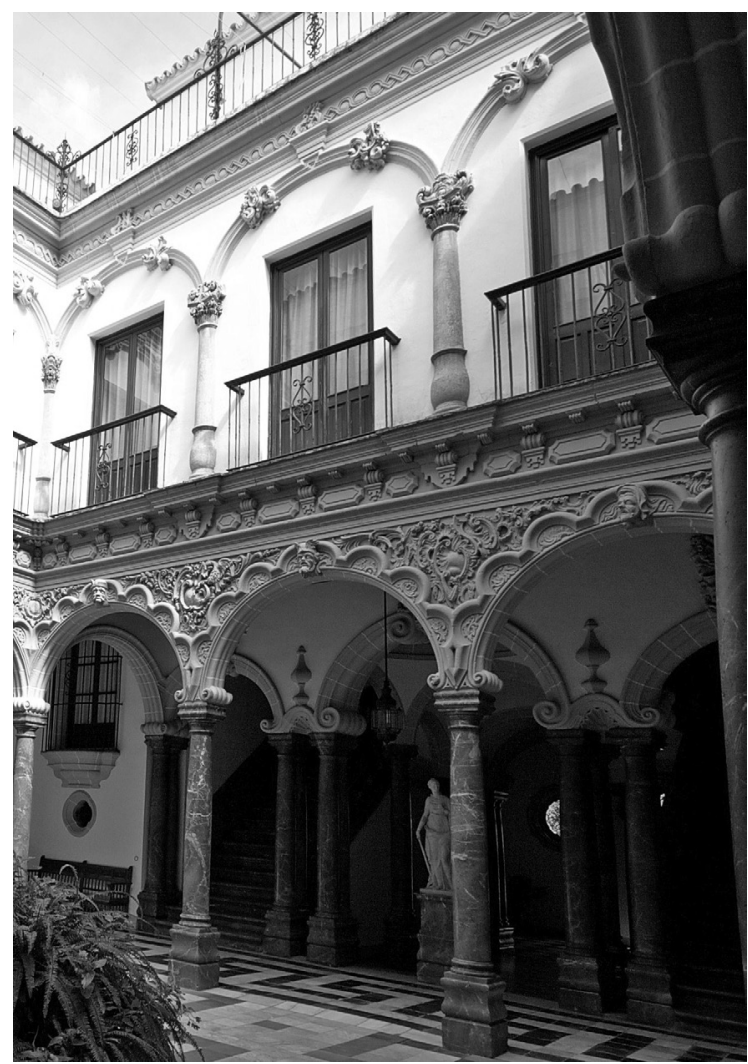

aceptando las importantes diferencias que también hay entre ellos, este otro gran ejemplar de la arquitectura civil jerezana de la época parece claro que sirvió como modelo para la concepción de la portada y del patio principal de la casa de Antonio Cabezas. Ello llevó a Sancho Corbacho a ver en ambas al mismo arquitecto ${ }^{46}$ y ello nos animó a plantear la posibilidad de que este fuera Juan de Bargas, cuando descubrimos que fue él quien dirigió las obras de Bertemati ${ }^{47}$. Lo que sí parece evidente es que esta última casa debió de suponer un gran impacto en la ciudad, siendo presumible que Cabezas exigiera a Juan Díaz que se basara en ella a la hora de idear el diseño de su vivienda ${ }^{48}$.

46 SANCHO CORBACHO, Arquitectura..., p. 329.

47 MORENO ARANA, "Notas...", pp. 99-100.

48 No obstante, cabe preguntarse si se puede descartar algún tipo de intervención de Bargas en las trazas que ejecuta Díaz. Llaman la atención los contactos que sabemos que tuvo Juan de Bargas con el marqués de Montana y su palacio. Así, en 1777 Bargas otorga una escritura de obligación a favor del 


\section{El arquitecto Juan Díaz de la Guerra: nuevos datos biográficos y profesionales}

Uno de los aspectos más peculiares de la biografía de este arquitecto son sus orígenes familiares. Aunque Repetto Betes aportó la referencia a su nacimiento y el nombre de sus supuestos padres ${ }^{49}$, la documentación que hemos localizado viene a demostrar una realidad diferente. $Y$ es que hay que empezar indicando que el bautizo de Juan Díaz no quedó reflejado en ninguno de los libros de bautismos de Jerez hasta el momento de su boda con Isabel de Pina en 1756. Es entonces cuando, a través de un mandato del vicario general del arzobispado hispalense, se logra que los curas de la iglesia de San Juan de Letrán anotasen su partida bautismal "por uno de los días del mes de Agosto del año de mil setecientos i catorze». Allí se afirma que era hijo de Antonio Sánchez y María Jerónima Collantes y que actuó como su padrino Diego de Pina ${ }^{50}$, seguramente familiar de su futura esposa. Sin duda, con esta maniobra un tanto heterodoxa se pretendía esconder una verdad incómoda, que no era otra que la condición de bastardo de Díaz. De este modo, podemos probar que su verdadero padre no se Ilamaba Antonio Sánchez sino Andrés Díaz, quien en su testamento, otorgado el 22 de diciembre de 1763, lo reconoce como hijo natural ${ }^{51}$.

Lo anterior nos permite además confirmar el parentesco, ya sugerido por Repetto Betes ${ }^{52}$, que unió a Juan Díaz de la Guerra con el homónimo obispo de Mallorca y Sigüenza. Este célebre religioso ilustrado, nacido en Jerez en 1726, era hijo de un maestro de obras Ilamado Antonio Díaz de la Guerra ${ }^{53}$. En 1777

marqués en la que se declara deudor suyo tras haberle prestado 11.000 reales para saldar cierta deuda (APNJF, legajo 2761 bis, oficio IV, escribano Pedro Caballero Infante, año 1777, f. 32). Sin embargo, es difícil de valorar si esta relación fue estrecha o puntual, ya que no es la única escritura en la que vemos al marqués ejerciendo de prestamista de diversas personas (APNJF, legajo 2832, oficio IX, escribano Francisco Fernández Gutiérrez, año 1784, ff. 185, 276). En segundo lugar, es Ilamativo que para el aprecio del palacio que se efectúa tras la muerte de Cabezas en 1786 los dos arquitectos que son llamados para la tasación sean precisamente Juan Díaz y Juan de Bargas (AROCA VICENTI, Estudios..., p. 41, nota 8). En todo caso, por ahora es imposible juzgar si estamos o no ante dos noticias meramente casuales. 49 REPETTO BETES, José Luis, La obra del templo de la Colegial de Jerez de la Frontera, Cádiz, Diputación de Cádiz, 1978, pp. 187-188, nota 6.

50 Archivo Histórico Diocesano del Obispado de Asidonia-Jerez (en adelante: AHDJ), Fondo Parroquial, Iglesia de San Juan de Letrán de Jerez de la Frontera, Bautismos, libro 30, f. s/n.

51 Declara que «siendo soltero y libre de matrimonio huve y tengo por my hijo natural a Juan Diaz de la Guerra que oy es Maestro de Albañil y será de edad de quarenta y seis años más o menos que huve en una mujer también libre de matrimonio con quien sin embarazo ny reparo pude haverlo contraido por que era tan conosida y de iguales circunstancias a las mias que por su honor, recogimiento y estimación y honestidad omito su nombre" (APNJF, legajo 2646bis, oficio VI, escribano Diego Flores Riquelme, año 1763, ff. 990-992).

52 REPETTO BETES, La obra..., pp. 187-188, nota 6.

53 PARADA Y BARRETO, Diego, Hombres ilustres de Jerez de la Frontera, Jerez de la Frontera, 1875, p. 126. 
este último emite su testamento. La información que suministra permite asegurar que era hermano del aludido Andrés Díaz y que, por tanto, el arquitecto del palacio Domecq y el obispo jerezano eran primos ${ }^{54}$. Unas novedades que no permiten, sin embargo, aclararnos aún cómo se desenvolvieron sus años de infancia y, muy especialmente, de formación profesional. El ser hijo bastardo debió de alejarlo de su padre, quien se casó posteriormente hasta dos veces, teniendo una serie de hijos legítimos de ambos matrimonios, a los que, a diferencia de él, nombraría herederos en el referido testamento. Con todo, el hecho de contar con un tío del mismo oficio parece haber sido decisivo para nuestro arquitecto, quien tal vez pudo formarse a su lado ${ }^{55}$. Sea como fuere, el contraste entre Juan Díaz como hijo ilegítimo y su familia paterna debió de hacerse acusado tras el meteórico ascenso social de su primo. De hecho, uno de sus hermanastros sabemos que optó por la carrera militar y llegó a ser teniente capitán del Regimiento de Dragones de Almansa ${ }^{56}$.

Pese a ello, Juan Díaz de la Guerra logró ganarse una posición relevante dentro de la arquitectura jerezana de la segunda mitad del siglo XVIII, consiguiendo dirigir algunas de las más importantes obras de su tiempo. De este modo, construyó la iglesia del convento de San Francisco $(1771-1787)^{57}$ y se hizo cargo de destacados edificios civiles, como la actual bodega Conde de los Andes $(1770)^{58}$, el Palacio de Villapanés (h. 1766-1776) ${ }^{59}$, además del propio Palacio Domecq. Cabe recordar también que desde 1783 hasta su muerte en 1795 ejerció de maestro mayor de la ciudad ${ }^{60}$.

Pero antes de la gran actividad que alcanzaría en torno a los años setenta, lo vemos encargado de labores más modestas. El primer trabajo que hemos po-

54 Por los testamentos de Andrés y Antonio Díaz sabemos que los padres de ambos se llamaban Juan Díaz de la Guerra y Catalina Cordero. En la última voluntad de Antonio hay un buen número de referencias al entonces obispo de Sigüenza (APNJF, legajo 2775, oficio VI, escribano Diego Flores Riquelme, año 1777, f. 137-140).

55 De la trayectoria de Antonio Díaz de la Guerra es poco lo que se sabe. Creemos que debe ser identificado con el Antonio Díaz que se encargó de ejecutar la restauración y reforma que sufre la iglesia de San Dionisio entre 1729 y 1732 (GARCÍA PEÑA, Carlos, Arquitectura gótica religiosa en la provincia de Cádiz: diócesis de Jerez, Madrid, Universidad Complutense de Madrid, 1990, p. 415. AHDJ, Fondo Parroquial, Parroquia de San Dionisio de Jerez de la Frontera, Fábrica, Visitas, año 1733, p. 200). En las crónicas sobre la etapa como obispo de Mallorca de su hijo (1773-1777) se narra una visita suya a la isla y se dice que era "maestro mayor de obras reales de Jerez de la Frontera" (ROSSELLO LLITERAS, J., "Don Juan Díaz de la Guerra (s. XVIII)", Estudios Iulianos, n. ${ }^{\circ} 28,1988,61-62$ ).

56 Se llamaba también Juan Díaz de la Guerra y se le cita con tal rango militar en una escritura (APNJF, legajo 2730, oficio XII, escribano Felipe Rodríguez, año 1773, f. 45).

57 AROCA VICENTI, Arquitectura y urbanismo..., pp. 230-234.

58 AROCA VICENTI, De la ciudad..., pp. 110-115.

59 MORENO ARANA, "Aportaciones...", pp. 157-181.

60 lbid., pp. 174-175. 
dido documentarle es de 1752 y consistió en la dirección de las obras de albañilería previas a la colocación del retablo mayor de la parroquia de Santiago, tallado por Francisco Camacho de Mendoza ${ }^{61}$. En 1769 se encargó de la restauración de la cubierta y bóveda de yeso de la nave central de la iglesia de San Lucas. Al año siguiente efectuó asimismo ciertos reparos sobre una casa propiedad de esta antigua parroquia ${ }^{62}$.

Por último, hay que recordar otras realizaciones ya publicadas, como la reforma de la sacristía de la parroquia de San Marcos (1770) ${ }^{63}$; una bodega en la calle Ponce y una casa desaparecida en la calle Rodalabota, ambas construcciones para el convento de la Victoria (1770)64; la reforma de la capilla del Hospital de la Sangre, hoy Asilo San José (1774-1776) ${ }^{65}$; y una serie de reparos sobre el conocido como Puente de Cartuja (anteriores a 1783) ${ }^{66}$.

61 AHDJ, Fondo Parroquial, Parroquia de Santiago de Jerez de la Frontera, Fábrica, Visitas, año 1755, pp. 103-106.

62 AHDJ, Fondo Parroquial, Parroquia de San Lucas de Jerez de la Frontera, Fábrica, Visitas, año 1772, pp. 97-102.

63 AROCA VICENTI, Arquitectura y urbanismo..., p. 222.

64 MORENO ARANA, "Notas...", pp. 100-101. Quizás la bodega se conserve dentro del antiguo conjunto bodeguero de Valdespino.

65 SERRANO PINTEÑO, Javier, "Reformas barrocas en el Hospital de la Sangre de Jerez de la Frontera: Juan Díaz de la Guerra y Rodrigo de Alva», Revista de Historia de Jerez, n. ${ }^{10,}$ 2004, pp. 105-112.

66 MORENO ARANA, "Aportaciones...", p. 175. Igualmente, podría ser el autor de otra casa desaparecida, emplazada en la esquina de la plaza de las Angustias con calle Corredera y fechada en 1774 (ibid., p. 174). 